\title{
Article \\ Co-Designing with Migrants' Easier Access to Public Services: A Technological Perspective
}

\author{
Grazia Concilio $^{1}{ }^{(\mathbb{D}}$, Giuliana Costa ${ }^{1}$, Maryam Karimi ${ }^{1, *(\mathbb{D}}$, Maria Vitaller del Olmo ${ }^{2}$ and Olga Kehagia ${ }^{3}$ \\ 1 Department of Architecture and Urban Studies, Politecnico di Milano, 20133 Milan, Italy; \\ grazia.concilio@polimi.it (G.C.); giuliana.costa@polimi.it (G.C.) \\ 2 Service Design Lab, Department of Architecture, Design and Media Technology, Aalborg University, \\ 2450 Copenhagen, Denmark; mvdo@create.aau.dk \\ 3 Department of Economics, University of Thessaly, 38333 Volos, Greece; ok@uth.gr \\ * Correspondence: maryam.karimi@polimi.it
}

Citation: Concilio, Grazia, Giuliana Costa, Maryam Karimi, Maria Vitaller del Olmo, and Olga Kehagia. 2022. Co-Designing with Migrants' Easier Access to Public Services: A Technological Perspective. Social Sciences 11: 54. https://doi.org/ $10.3390 /$ socsci11020054

Academic Editor: Carlos Teixeira

Received: 19 November 2021

Accepted: 21 January 2022

Published: 29 January 2022

Publisher's Note: MDPI stays neutral with regard to jurisdictional claims in published maps and institutional affiliations.

Copyright: (c) 2022 by the authors. Licensee MDPI, Basel, Switzerland. This article is an open access article distributed under the terms and conditions of the Creative Commons Attribution (CC BY) license (https:// creativecommons.org/licenses/by/ $4.0 /)$.

\begin{abstract}
The integration of migrants, refugees, and asylum seekers remains a challenge for both public authorities and local communities at the national, regional, and local levels. For migrants, the lack of information and inability to use technology due to insufficient access skills and proficiency in the language of the host country may lead to limited interaction with the new community and consequently to social exclusion. One of the issues of the hyper-complexity in migrant integration can be related to a problem of communication that not only involves the migrants also the local administrators and service providers. This problem requires systemic solutions rather than simple "ad hoc" solutions. This article describes the case of the easyRights project, an ongoing Horizon 2020 project aimed at improving migrants' access to public services to ease exercising their rights. It presents the application of a co-design learning framework for the development of hackathons that aim to improve existing services. It also promotes the collaborative design of solutions that use ICTs to overcome the bureaucratic and idiomatic barriers migrants experience in their interactions with formal procedures. The example of the four ecosystems generated in the four pilot cities of the project shows the relevance of interconnecting stakeholders in the co-design of services and the potential of exploiting the multifaceted attributes of ICTs to solve the complexity in the access to such services. The results invite reflection on the necessity of exploring the capability of technology application through user-centric approaches to offer substantial solutions to the imperative-yet intricate—challenge of migrants' inclusion in society.
\end{abstract}

Keywords: services for migrants; service accessibility; ICT services co-design; easyRights project; social inclusion

\section{Introduction}

\subsection{Integration: A Multifaceted Problem of Access to Rights}

"You've made it, you've managed to leave your country. You are in Europe, but your travel hasn't finished yet. You still have a long journey ahead of you to get to know the new hosting country's societal institutions, culture, socio-economic settings. You'll have to orient yourself and try to grasp how to live where you are, accessing the different kinds of resources required for your daily life. You'll have to learn a new language. You'll have to understand what your rights and duties are. And you'll need to be oriented in this journey $^{\prime 1}$. This statement highlights the complexity of issues that are part of the experience of migrants and also of the volunteer and administrative staff dealing with them.

Many studies and research addressed the dimensions and factors that affect people's decisions to leave their country and become migrants (see, for example, Feldman 2020; Fertig and Schmidt 2001; Vargas-Silva and Rienzo 2019). To a lesser extent, the issues and concerns on the integration of foreign individuals and their families into unknown, diverse, distant, and sometimes rather hostile societies have been critically observed and 
studied. Meanwhile, an increasing number of voices -mainly from the community of migrants- has been asking for more reflexivity on the fundamental crisis in integration and migration debates by criticising the exclusion of non-citizens and the institutionalisation of discrimination (Dahinden 2016). This existing gap is even more surprising if one considers the recent efforts that have been made by governments around the world in developing new policies, administrative rules, and affirmative actions to promote and procure immigrants' integration into the hosting countries and cities (OECD 2016, 2018).

Indeed, the concept of migrants' integration has changed in the meantime, from being merely "accepted" as newcomers to becoming acknowledged and valuable individuals of the new country's society, labour market, welfare system, cultural environment, etc.albeit with different schemes, adopting a more assimilationist, multiculturalist, or postmulticulturalist perspective. In addition, it has been argued that the multifaceted and multi-dimensional process of integration can improve when the different actors, including the host communities and migrants, understand and appreciate each other's primary aims and constraints, which can ease the process to deal more effectively with the challenges of migration and integration (Ruhs et al. 2019).

Vertovec's (2007) definition of "super diversity", introduced at that time to underline a level and kind of complexity surpassing anything the UK had previously experienced, can easily be extended to the majority of EU countries today. It makes implicit reference to the dynamic interplay (if not clash) of a huge number of aspects displayed by the immigrant profiles and the receiving countries' laws and regulations, which play an important role in determining integration obstacles. Such aspects include differences in the countries of origin, cultural values and practices, the various migration channels used, human and social capital specificities (including language and digital literacy) as well as differences in the legal status (i.e., refugees and asylum seekers vs. socioeconomic or irregular migrants, each of them with their own set of entitlements and restrictions). As a result of that interplay, the various national policies and programs designed to cope with immigrants' needs have determined, de facto, a plethora of heterogeneous forms and levels of integration (OECD 2018).

To complete this picture, there is evidence that the construction of immigrants' integration and inclusion, as well as the recognition and management of cultural diversities (Foner 2007), are more and more defined and implemented at the local level (Finch 2016; Costa and Ewert 2014; Scholten et al. 2017; Caponio and Jones-Correa 2018). There, municipal authorities and other local government bodies play a decisive role in building inclusion, as well as exclusion, patterns by simply facilitating or making more complex what Isin and Nielsen (2008) call "acts of citizenship", which include both the outcomes of discretionary decisions and compliance with implementations of mandatory national or supranational administrative procedures. Increasingly, the margins for interpretation or 'manoeuvre' at the local level of the superimposed regulations from the national level led to further differentiate the actual pathways of inclusion and create new and substantial gaps between the dimensions of citizenship and integration (OECD 2018; Schiller and Çaglar 2011). For this reason, it is necessary to ensure equal access to services as well as to provide flexible and adaptable solutions to cope with the needs of migrants that can ease and quicken the integration process. The following section elaborates on this aspect of integration in more detail.

\subsection{Services as Interfaces towards Rights}

Rights are normally considered valid if there is someone with counterparty obligations. In the meantime, the validity of the rights seems to be interpretable and enforceable within relations and/or interactions with the mechanisms put in place to guarantee the rights themselves; the mandatory existence of such mechanisms implies the existence of the value of rights. As a matter of fact, we normally consider null, indeed indefinite, claims or rights that cannot be guaranteed by any mechanism, which no one is obliged to honour or cannot be implemented. If we look at rights as an artefact that interprets human aspirations and 
desires, it is possible to run the risk of moving into the domain of their invalidity due to the lack of mechanisms ("how") and subjects ("who") that obligatorily guarantee them. Otherwise, if we look at rights as a normative artefact, it is possible to look at rights from the point of view of the obligations to be considered in order to guarantee them. That is why, within a regulatory approach to rights, mechanisms and/or subjects obliged to guarantee them are fundamental (see O'Neill 2005).

The increasing migratory dynamics and the changing geographies of migrants' permanencies put a strain on both national governments and local authorities in the implementation of inclusive policies in general and in the creation and maintenance of mechanisms and subjects that contribute to inclusion by guaranteeing people's rights. In this article, and in general, in the Horizon 2020 easyRights project, we look at services as interfaces between rights and people with a special focus on immigrants. In this vision, the easiness of access to services can be interpreted as an effective proxy to the value guaranteed to a specific (immigrant') right. In this sense, services are touchpoints of mechanisms or subjects entitled to guarantee people's rights, and their ease of access determines the value and tangibility of these rights.

The idea of services (especially public ones) as interfaces between people and their rights is not a widely debated topic in the service-related literature. Still, the link between public services and human rights has been explored in the years of the worldwide process of their privatisation (Sullivan 1987; Moe 1987). The discussion has proven the relevance of the role played by the service providers (when distinguishing between private and public actors), adding complexity to the discussion on the guarantee (formally "who and how?") of rights. Privatisation of processes required service provision and service-related decisions on service practices (Abramovitz and Zelnick 2015) to be reshaped, and this has been acknowledged by some scholars as having relevant potential impacts on human rights that are related or affected by specific services (Feigenbaum and Henig 1994). By observing that privatisation "has failed to deliver adequately on efficiency, equity or voice criteria", Warner (2008, p. 163) highlights, for example, the role of services as means to assure basic human rights, such as equity. Considering services as interfaces towards rights is therefore not a full novelty and is proving to be a fertile manner to manage service design and/or service digitisation.

Indeed, the greatest difficulty for the average immigrant is learning where and how to find information on the type of services available, their specific locations, and how to access them. This difficulty is magnified by the fact that those services are usually immersed in a system of norms and rules that regulate the relations between people and institutions. Most of these norms and rules are taken for granted by autochthonous citizens, who are typically sufficiently aware of the norms and know how to deal with the innumerable unexpected issues that may emerge along the way. This is obviously not the case for the immigrants - especially newcomers - which adds to the feeling of uncertainty and insecurity they already have.

It is not by chance that, according to a report published by Eurodiaconia ${ }^{2}$ in 2014 , the second of the three top challenges for migrants in Europe ${ }^{3}$ is related to administrative and legal complexity (Eurodiaconia 2014). The Horizon 2020 project easyRights holds this complexity challenge at its core. It considers that for the newcomers in a host country, like for any other regular citizen, the exercise of rights and access to public services can be facilitated through user-centred redesign and reengineering. It also considers the specificities of these specific users. Through customised, efficient, and effective access to services and therefore through acknowledgment and exercise of rights, easyRights aims at concretely contributing to the goal of migrants' integration into the respective hosting communities (easyRights D1.5 2021). The overall goal of easyRights is to ease service access for migrants and therefore improve access to rights. In unison with the many studies and practices in the field that have proved that co-creation is crucial for innovating and adopting solutions for migrants, this perspective is adopted by the easyRights project (Joint Migration Policy Whitepaper 2020). 


\section{Immigrants and Information and Communication Technology Supportive Tools and Platforms}

The links between migration, integration, and the use of Information and Communication Technology (ICT) tools by immigrants, as well as by governmental and civic institutions working with immigrants, are addressed in various international studies (Codagnone and Kluzer 2011; Diminescu 2008). Migrants encounter several obstacles along their voyages towards integration, including cultural barriers, low understanding of local language, behaviour, and practices, and a lack of (reciprocal) trust. These barriers, amongst others, often result in migrants' social isolation, poverty, as well as limited access to basic and crucial services, such as health and social care or housing opportunities. To deal with these critical experiences, technological solutions have been developed to support migrants in enhancing their abilities and capacities to face these obstacles and improve their conditions. Technologies, in fact, appear to enable numerous capabilities, help migrants during their daily life activities in their new environment, support informal language learning and integration, and aid migrants in reducing the fears and uncertainties they have about the new place where they live (Spotti and Kurvers 2015). Technologies can support them in their journey to integration (Collin and Karsenti 2012).

According to the revised Lisbon Agenda in 2010, everybody living in Europe, especially disadvantaged people, should have the opportunity to use ICTs (Hachè and Cullen 2009). Building on this, the 2006 Riga Declaration on Inclusion defined inclusion in this regard as meaning "both inclusive ICT and the use of ICT to achieve wider inclusion objectives" and selected, out of six priorities, the promotion of cultural diversity in Europe by "improving the possibilities for economic and social participation and integration, creativity and entrepreneurship of immigrants and minorities by stimulating their participation in the information society" (Codagnone and Kluzer 2011, p. 7). In the light of these goals, the Institute for Prospective Technological Studies carried out a study to explore ICT's adoption and its use by immigrants and ethnic minorities (IEMs) in Europe and the related policy implications (Codagnone and Kluzer 2011). According to the authors, ICTs are crucial for IEMs to make a living and increase their chances in the social and economic context in which they live. Moreover, ICTs help migrants keep in touch with their family and social networks in the homeland and elsewhere. The motivation to learn and use ICTs among IEMs is therefore very strong. ICTs skills often have a direct relation to the socio-economic status, educational level, and place of residence of the people involved. Particularly, the lack of host society language skills, lack of enough education, and lack of interaction and access to ICTs increase immigrants' exclusion and isolation (Farbenblum et al. 2018).

In addition, ICTs can play an important role in the employability and integration of immigrants in the EU (Reichel et al. 2015). In their study, Reichel and his colleagues focused on three European countries (Bulgaria, the Netherlands, and Spain) and their efforts to use ICTs to integrate the immigrants and help them find a job. The migration history, as well as the integration policies and the levels of integration of immigrants, played an important role in the selection of these three countries. It also states that the main causes of digital inequalities are age, education, level of employment status, and type of occupation of people. Some studies explored the role of skills in advancing employment opportunities for immigrant women in five countries (i.e., Italy, Spain, the Netherlands, Hungary, and Romania), and to which level of digital competency and ICT use can serve as an indicator for broader and social inclusion (Garrido et al. 2009).

Finally, a study conducted by Deloitte in 2019 for the European Commission examines how administrations can adopt (innovative) ICTs to ease the journey and integration of migrants, making use of electronic identification (eID) to facilitate their access to services (Deloitte 2019). Based on the analysis of 12 case studies, the report identifies trends in the use of innovative ICTs for this purpose and best practices for future initiatives. The EU could engage with this initiative to learn more about the difficulties and bottlenecks regarding the cross-border sharing of data, as well as privacy issues. 
Despite the large number of ICT solutions developed and being available for immigrants, many problems persist. In a dedicated literature review, Bustamante et al. (2018) identified the most important challenges that migrants face when interacting with local services. They used these challenges as general categories to analyse the reports of several interviews conducted to assess a set of ICT solutions targeting migrants' difficulties. In this study, the initial challenges were categorised as language, functional, information and technological complexity. Further in their conclusion and in the discussion of the specific results of the interviews, they identified other subcategories of challenges in relation to the use of geospatial services and type of information visualisation (Bustamante et al. 2018).

\section{The easyRights Project}

\subsection{Project's Visions and Goals}

The overarching objective of easyRights is to develop a co-creation ecosystem in which different actors belonging to the local governance system can cooperate to increase the quantity and quality of public (welfare) services available to immigrants. The specific aims are to improve the current personalisation and contextualisation of services, empower the prospective beneficiaries of existing services in obtaining better access and fruition opportunities, and engage Quadruple Helix ${ }^{4}$ stakeholders in joint, purposeful co-creation efforts facilitated using hackathons (easyRights D3.1 2021). The easyRights vision combines the similar meanings of "aggregation of local stakeholders" and "collection of online and offline services" and is being developed and deployed in four pilot locations, namely Birmingham, Larissa, Palermo, and Malaga. In doing so, easyRights supports immigrants in their search for responses to different needs, making them more autonomous-at least to some extent-from discretionary street-level bureaucracies, saving time for both migrants and for social service staff and cutting costs for the public administration. As a matter of fact, access to welfare services, especially for these groups, often requires face-to-face interactions and a strong, discretionary, street-level bureaucratic system (Lipsky 1980; Barberis and Buchowicz 2015).

Two key aspects are worth exploring and experimenting within the project, namely that on the one side, immigrants' integration is challenged by the complexities of international, national, and local norms that differentiate its mechanisms across the countries. On the other side, it is also the, albeit wrong, feeling that immigrants self-associate as "illegal" or "illegitimate" citizens' that acts as an impediment to a broader and fuller exercise of their acknowledged and endorsed rights. This feeling creates dangerous paradoxes. For instance, if we look at Italy, article 32 of national law ${ }^{5}$ allows doctors in the hospitals' emergency rooms to aid people who refuse identification. How known is that paragraph by irregular immigrants? Still today, we read stories in the press reporting about pregnant, sick, or injured (irregular) immigrants who prefer not to go to the hospital for treatment, with all the consequences that this decision may have.

Within our project, four pilot cities, namely Birmingham in the UK, Larissa in Greece, Malaga in Spain, and Palermo in Italy, have been identified to experiment with the easyRights proposed innovations. The selection of these cities was based on the high rate of migrants' acceptance through the years, their relatively diverse challenges towards migration, as well as the strong role of their municipalities and local actors in welcoming and integrating migrants into their communities. Moreover, we based our choice on other considerations. For instance, Birmingham is a "city of sanctuary" (Bauder 2016; Bauder and Gonzalez 2018), and it proudly welcomes people from all corners of the globe, regardless of their situation. Additionally, it is the most ethnically diverse regional city in the UK (Costa and Ewert 2014), with a population made up of 187 different nationalities (data provided by Birmingham City Council). Larissa is a city that coordinates the local network of volunteers, a network that includes both organisations (public and NGOs) and individuals. The city was the first Greek city to be included in the UNESCO Network of Learning Cities and was one of 16 world cities to be awarded the 2017 Learning City (data provided by the municipality of Larissa). The city of Malaga and the whole region is considered a territory 
with a very high and increasing number of refugees, but the city holds many challenges on social inclusion. Several reasons for that have been identified, such as language barriers, lack of training or easy access to the job market, and in many other cases, the reluctance of companies to hire refugees or migrants. Instead, the case of Palermo is quite different. In 2015, the city of Palermo drew up "The Charter of Palermo", in which the concept of the right to mobility is affirmed for all people and consequently the right to seek asylum to any immigrant (Messina and Sabato 2019).

The pilot teams worked to explore the existing services in each city from the stakeholder's perspective and reflected on how to address them in the easyRights agendas. Within two different and subsequent cycles of activities, easyRights targets four different services-one per city per each cycle (overall eight services within two cycles of activities) following the framework described above, in four different-yet closely related-steps. Each pilot mapped the existing (as is) and desired (to be) key administrative rules and procedures that pave the way for immigrants' access to services and enable them to exercise their rights while adopting the point of view (and the language) of prospective beneficiaries.

Improving language skills is a key precondition for the effective inclusion of immigrants (Collin and Karsenti 2012). This is carried out by expanding the web-based CALST platform ${ }^{6}$ focused on tailored pronunciation training (listening, speaking and writing). In combination with CALST, a specific focus and features on personalised vocabulary learning are added as well. Enhancing the effectiveness of communication and thus the immigrants' understanding of their fundamental rights, irrespective of legal status, is, in our understanding, a prerequisite for their insertion in the hosting society. This is supported by a multilingual Natural Language Understanding (NLU) system, aiming to overcome the communication problems of most government-led welcome portals ${ }^{7}$ by the implementation of artificial intelligence and machine reading capacities. The NLU system provides a semi-automatic interpretation of the instructions or rules contained in those portals, which are structured in the form of "what", "where", "how", and "when" specifications per each step of the procedures. Additionally, easyRights aims at introducing tailor-made service innovations in the context of multi-stakeholder hackathons conceived as collaborative co-design environments including public officials and users (immigrants) in addition to coders and service designers.

Literature shows that users' know-how matters when designing ICT-based services (especially when dealing with interfaces and data gathering) in a user-centred design process (Callahan 2006; Bobeth et al. 2013). Within the context of the four pilot cities, easyRights has already completed the first four steps cycle over four different services: registration to the register office in Palermo, request for asylum in Malaga, request for the certificate of residency in Larissa, and vehicle compliance with Clean Air Zone norms in Birmingham. In easyRights, a crucial consideration for better immigrants' integration and for the ease of exercising their rights is to work at improving services' accessibility together with migrants themselves and with the actors involved in the service provision process.

\section{2. easyRights Co-Design Approach}

Service design introduces human-centred approaches to designing or redesigning services (Rizzo et al. 2016). By looking at how services are designed and implemented, service design applies a user-centred process, understanding both the users' and stakeholders' needs and exploiting this knowledge to design the services interactions (Stickdorn et al. 2018). The service design process proceeds in four main phases: understanding the context as well as the stakeholders and other elements of a service; defining the problem according to the user needs; prototyping new solutions that respond to the identified criteria; testing and implementing the new service (Design Council 2007).

The process of service design can be assimilated to the well-known "design thinking" process (Brown and Katz 2019), and both advocate for the involvement of stakeholders, such as citizens or front-end operators, in the design of new solutions. Such solutions are therefore expected to come from actors who are not used to "designing" their own services. 
The involvement of such non-traditional actors in the process is applied in service design as a relevant source of inspiration for innovative ideas; their way to improve existing services or to compensate for their lack of efficiency is possibly part of the solution (Von Hippel 2005). However, the capacity to transform ideas into consistent and coherent solutions, as well as the capability of stimulating citizens' creativity, needs to be supported by proper tools that facilitate the various phases of the service development, from early ideas to service scenarios and to a service structure.

Thus, service design operationalises the design and implementation of services components by focusing its attention on the user's needs and experience interacting with them. Users are directly involved in service design to share their needs, stories, competencies, skills, and preferences. To involve the end-users and other stakeholders in the design of the different service components, the service design has developed a series of tools and templates (Rizzo et al. 2016) and capabilities that facilitate the access of such actors to the previously described design process, so they can effortlessly contribute to designing the specific components of the service from their expertise (Morelli et al. 2021).

By defining "personas"-archetypes of groups of users that share common goals, attitudes, needs, and behaviours towards the service-service designers summarize users' inputs and use them as a reference to (re)design services (Long 2009; Pruitt and Adlin 2006). Complementary, user journeys-representations of the user experience when interacting with the different touchpoints of a service-serve to make informed decisions on the specific areas of the service that need improvement and the reasons behind (Schneider et al. 2018). These two tools characterize the user-centric nature of service design.

Service design is also characterised by a systemic perspective, which states that the design or redesign of a service cannot be independent of the organisation that will deliver it. To implement this principle, service design makes use of service blueprints that represent the internal and external interconnections and dependencies between the user journey, the touchpoints, and the underpinned organisation.

In the case of the easyRights project, the tools supported the pilots in collecting relevant data and information of the targeted services to facilitate reciprocal understanding and collaborative work. Service design tools and templates were meant to support users - as experts in the service experience - to take an active part in the redesign of such services. These templates use visual representations to facilitate co-design participants to immerse themselves in the user-centric approach of service design and learn from it. Thus, the easyRights project proposes to combine advanced human-centred service design with a learning framework to set up a knowledge-creation space that affords pilots and stakeholders the ability to participate in the service (re)design processes described above.

In particular, easyRights implements an experiential learning cycle that includes, at the same time, the core structure of service design (which can be complemented with appropriate tools and applied to the co-creation of services) and of a learning process (Concilio et al. 2021). When considering the pilots not only as a closed structure, typically represented by a core actor (a municipality, a hospital, a public transportation service provider) but also as a network of actors, the learning process can be regarded as extending to the whole local community and can function through the aforementioned interactions.

In other words, through the application of service design approaches, the easyRights service ecosystems have gone through a process of service redesign from the perspective of users by delivering appropriate information and content for the entire project development. At the same time, they have been exposed to a learning experience aimed at supporting the different actors to develop a user-centric culture in the design of public services.

Within this co-design framework, the easyRights hackathons have been conceived as a participatory format where the different stakeholders collaborate in the redesign of the chosen services. The attributes of these hacking marathons-intense, experimental, lowrisk, and collective (Taylor and Clarke 2018; Carr and Lassiter 2017)_provided a reliable environment from where to start building solutions to improve migrants' experience in relation to the selected services. The traditional hackathons format had to be, however, 
adapted in terms of its target, goals, and extension to fit the project aim. Regarding the target, contrary to traditional hackathons, easyRights ones were open not only to hackers, coders, and technical experts (considered "solution owners") but also to migrants, social workers, lawyers, and other experts on migration (the "problem owners"). This was the only way to guarantee solutions that responded to the challenges and issues identified in the service, and therefore an ulterior adoption by the migrant community.

In terms of the goal, the easyRights hackathons had a stronger business orientation than regular hackathons, as the solutions had to fit in the procedures and regulations of an already existing public service. This implied that the presented challenges were remarkably detailed in terms of the scope and the conditions of the expected solutions, leaving less room for experimentation and creativity in favour of operation.

The traditional short-term format of a hackathon was also altered. To comply with the understanding of the specificities and problems migrants face when dealing with the service, with the involvement of the multitude of stakeholders involved in it and with the ulterior integration of the hackathon solutions in the existing services, the format of easyRights hackathons was extended. Thus, the easyRights hackathons are established as a package of activities divided into three phases, each considered equally relevant for the successful contribution of the hackathon cycles to the improvement of the services (see Figure 1). They consist of an extensive process of preparation (pre-hackathon), the event happening (hackathon), and an additional development phase (post-hackathon).

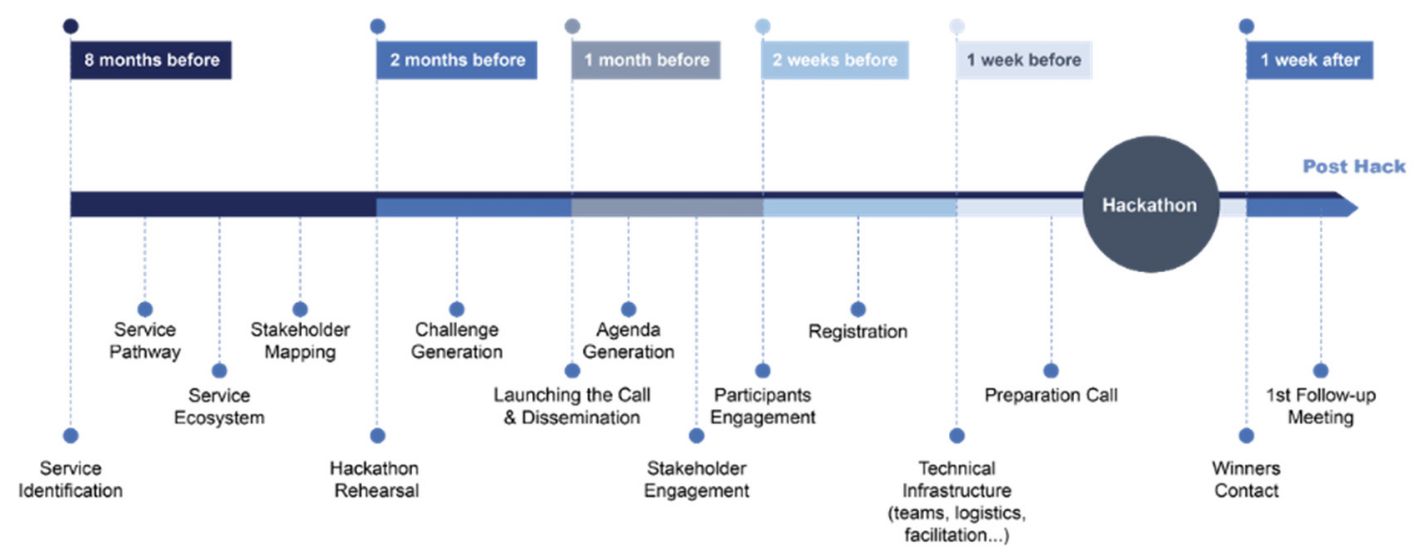

Figure 1. Timeline of the easyRights co-design process (easyRights D3.1 2021).

The pre-hackathon started with an initial identification of the services to work on, followed by the analysis of the service pathway to diagnose the gaps, barriers, and actors that migrants face in their interaction with the service procedures. Additionally, this was the phase to envision and consolidate the three essential pillars to run a hackathon: the challenge, the people, and the technical aspects. It encompassed the recruitment of participants, the challenge framing for the event, the set-up of the infrastructure, the agenda formation, the preparation of supporting materials, and the alignment of the task force (speakers, mentors, facilitators, jury).

All the easyRights hackathon events lasted 3 days and followed a similar structure: one day for the introduction of the challenge and the team's initial ideas, one day focused on the idea development and iteration, and the last day for the final iterations, presentation, and selection of the winning ideas. The post-hackathon phase started as soon as the events concluded and lasted some additional months to allow the teams to start an active collaboration with the service owners and the municipal offices.

It is important to mention that the first cycle of the easyRights hackathons described in this article was affected by the outbreak of the COVID-19 pandemic. This was an unexpected perturbation that has heavily impacted the organisation of the hackathons. As the essential condition of a physical hackathon-the concentration of people to work together 
in the same space-was no longer possible, the hackathons were adapted to online formats. The easyRights consortium counted with no experience on online hackathons, but the references of virtual hackathons by the European Commission to find collaborative and creative solutions to address the global health emergency (e.g., The Global Hack, The EuvsVirus Hackathon, Design with Data) served as positive inspiration for the feasibility of migrating these co-creative events we envisioned while keeping the interactive and participatory atmosphere of physical hackathons. However, even if removing the physical barriers meant that participants could be located anywhere in the world-enlarging enormously our potential target group - all pilot cities found severe difficulties engaging enough participants in the events. Additionally, the online format entailed a collection of unfamiliar challenges and strategies in terms of the infrastructure and management of the events.

\section{Working Methods within the easyRights Ecosystems}

\subsection{Starting the Exploration of Existing Services}

The pilot teams worked to explore existing services in each city from the stakeholders' perspective and reflected on how to address them in their easyRights agendas. Background research included 63 interviews to different stakeholders (municipalities, NGOs, immigrants and other local authorities or influential institutions) in which the pilots came up with a detailed description of the as-is and to-be service situations, with and without the support of the project's solutions. Each pilot identified two relevant services to set the stage and pave the way for the project to achieve its goals in the local context.

Further, the adoption of a service design approach allowed quickly sharing a common language among the pilots as well as-although less rapidly-among the easyRights partners, easily capturing the users' points of view (those whose access to services is in the project target), and effective dialogue with technology providers that allowed the ICT partners to identify the target directions in the development of the easyRights solutions.

Throughout two initial workshops, and for each of the identified services, each pilot could identify the service procedures, back-office operations, weaknesses in relation to users' needs, and opportunities for improvements at the organisational and technological level, thus creating the pathways towards changes in the service provision that targeted both the easing of access and, at the same time, a purposeful innovation of those services. Using dedicated templates (see Table 1), pilots were asked, in a first workshop, to map (even at an assumption level) the service procedures, key problems in the service use and the stakeholders' network (actors engaged or involved in the service delivery). In a second workshop (using idea cards templates), pilots have identified a first draft of a "to-be" scenario for the services.

Table 1. Two workshops for services' exploration.

\begin{tabular}{|c|c|c|}
\hline & $\begin{array}{l}\text { Workshop } 1 \\
\text { Service Description (as-Is) }\end{array}$ & $\begin{array}{l}\text { Workshop 2: } \\
\text { Service Description (to-Be) }\end{array}$ \\
\hline Objective & $\begin{array}{l}\text { Producing a description of the "as-is" situation, including the } \\
\text { policies the organisational dimensions, the challenge, and the } \\
\text { current ways to face the challenge. }\end{array}$ & $\begin{array}{l}\text { Producing a description of the "to-be" scenario, including } \\
\text { improvements and changes to be introduced in the context and } \\
\text { the services that can support the pilots to better address the } \\
\text { challenge. }\end{array}$ \\
\hline Methodology & $\begin{array}{l}\text { The methodology used is reverse engineering (using } \\
\text { problem description template): going back to the main } \\
\text { contents: context, challenge, service/s. } \\
\text { Key targets: missing information to be included/added; } \\
\text { quality of descriptions or model of representation of } \\
\text { current solutions. }\end{array}$ & $\begin{array}{l}\text { - The methodology used is the what-if scenario (using an } \\
\text { idea card template). } \\
\text { Starting from the service's main weaknesses and } \\
\text { strengths, envisioning improvements depending on } \\
\text { technological solutions; services process; competencies } \\
\text { and structure of the organisation. }\end{array}$ \\
\hline Output & $\begin{array}{l}\text { - A description of the services. } \\
\text { Analysis of the service context and service-related } \\
\text { problems. } \\
\text { - Starting definition of the challenge. }\end{array}$ & $\begin{array}{l}\text { - A detailed list (draft) of the weaknesses to be addressed } \\
\text { within the scope of easyRights. } \\
\text { - An initial list of users' requirements and wishes } \\
\text { - An initial list of possible new stakeholders to be involved. }\end{array}$ \\
\hline
\end{tabular}




\subsection{Activating the Service Ecosystems and Preparing the Hackathon Challenges}

After the first two workshops, the pilot teams continued to deepen the exploration of one of the two selected services, namely those to be the target for the first cycle activities, by directly involving service-related actors. On site, the four pilots carried out diverse activities and collected additional information through interviews and co-design meetings with immigrants, internal staff involved in service delivery in the municipal offices (people responsible for the different steps of the identified procedures) and with other actors engaged in non-governmental organisations and supporting immigrants throughout the service interaction process. Several of these activities were also involving the easyRights ICT partners. These activities had a double effect. First, they raised attention towards the project (a sort of indirect dissemination effect). Second, they started the activation of the local Quadruple Helix community in relation to the identified services/procedures (community activation).

A Quadruple Helix ecosystem refers to constructive interactions among national and/or local government, academia, business, and the public (Carayannis and Campbell 2009). In the case of easyRights, these ecosystems are shaping the pilot sites, covering societal (civic and legal), organisational (town hall related), and behavioural (individual migrants related) aspects (Concilio et al. 2021). The easyRights Quadruple Helix ecosystems are networks that activate complex relations between the different actors and have their power engines in the pilot activities. In other words, knowledge and innovation activities in easyRights can be seen as characterised by a pluralism of cross-cutting multi-level interactions from organisations active at the local level up to the national one and, in some cases, up to transnational ones (see Figure 2).

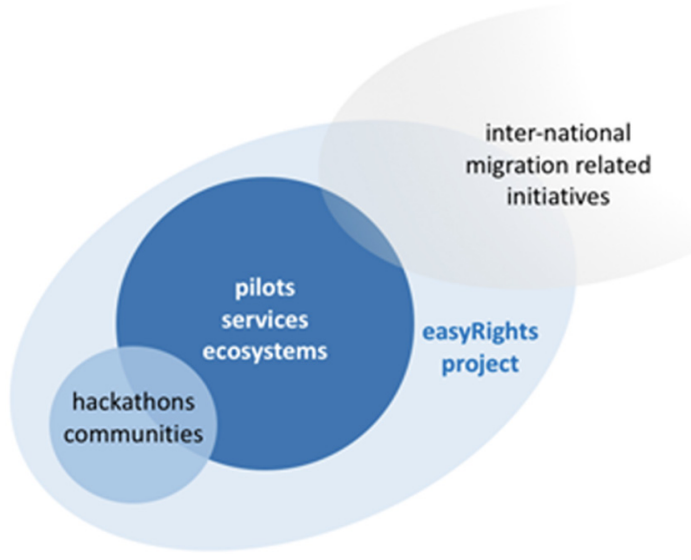

Figure 2. Towards a multilevel Quadruple Helix community (source: easyRights D5.1 2020).

The creation of Quadruple Helix ecosystems, and the consequent emergence of effective alignment dynamics among them, is enabling easyRights to further implement institutional collaborations and to consolidate strategic alliances in the local context. The high importance of a constantly ongoing process of construction, expansion and connection of the ecosystems results from their operationalisation as innovative and dynamic learning environments for all actors.

The pilots set out the following actions aimed at activating local service-related ecosystems:

(a) Engagement of stakeholders in interviews, workshops, or focus groups (overall, 63 interviews had been conducted within four pilots service ecosystems from June to September 2020) was shown to be a very helpful instrument to explore the service ecosystem, to prepare for the hackathons, ensuring no important actors are forgotten, and to remind pilots that the ecosystem is wider than and can be widened in respect to the perceived one. 
(b) Identification of active actors in the complex dynamics of service supply was needed to involve everybody in the design, as well as in the reflective process. This made the project activities a means to widen the service-related ecosystems.

(c) Collection of service experiences involving migrants at the service's interfaces to make them active resources in the service co-designed process as well as to engage them in the adoption of the solutions to be developed. (This has been conducted through the semi-structured interviews and set the plan for testing the solutions.)

(d) The widening of service ecosystems enlarges both the network of actors and the service technological infrastructures. The involvement of different local actors in the hackathon teams, opening the hackathons to a variety of different skilled figures (ICT experts, designers, lawyers, immigrants' supporters), allowed hackathons to continue the co-design approach activated locally.

The collection of information related to service experiences allowed the development of a service journey for each of the four services under the focus of the first project cycle. Each service journey describes procedures of each step: what really happens in the implementation of the step, the problems associated with it and distinguished per-type of involved actor, the person most affected by the problem, the eventual (as-is) existing technology associated with the step, and the potential use in it of one of the easyRights solutions.

The long co-design process implemented to capture key elements of the service journey represented a relevant learning moment for all the stakeholders involved in the service experience, both from the side of service use (immigrant users and supporting volunteers or organisations) and from the side of service provision (front or back-office service employees). Key learnings are represented by the service experience, as well as the obstacles, difficulties, and problems encountered from both sides when immigrants are involved.

\subsection{Hackathon Events and Solutions}

The hackathon events of the first cycle represented the first opportunities to widen the service ecosystems and include a larger community of developers and migration-related actors. They were rich and productive experiences not only for the pilot coordinators, who were anyway unfamiliar with hackathons but also for all the actors of the services ecosystems who shared an important experience together with immigrants and technology developers. All the participants were strongly engaged by the lively representation of the experiences migrants go through when accessing or using public services that are supposed to facilitate their life.

As previously introduced, shifting the hackathons to online formats due to the COVID19 pandemic severely affected the participation numbers. In all four pilots, the registration rates were significantly higher than the show-up rate in the events. Several reasons could have contributed to such a situation, being two the most troubling. On one hand, the timing of the events: three of the hackathon calls were launched before Christmas, and the hackathons occurred a couple of weeks after the holidays, difficulty to keep the engagement of registered participants for so long and impeding them to be aware of some important duties that came up since the moment of the registration until the event took place. On the other hand, the so-called Zoom-fatigue prevented many potential participants from joining as they already spent their weekdays interacting through a screen, participating in a fully remote event also during their free time was perceived as too demanding. However, even with low registration numbers, all hackathons managed to have at least one team working on the proposed challenges.

One of the peculiarities of the easyRights hackathons is the diversity of profiles in the targeted participants. The hackathons events were not exclusively open to technical profiles (coders and developers) but were also open to professionals in humanities and creative domains such as designers or experts in the problem area such as migrant support organisations, social workers, or other experts. The mix of profiles was clearly visible in the cases of Malaga, Larissa, and Palermo hackathons: the Malaga team was formed by 
one developer and two designers; one of the Larissa teams consisted of three developers, a project manager, a migrant and an expert in international relationships, while the Palermo teams included developers, a designer or project manager, and an expert in the migration field (a lawyer and a social worker).

The competence heterogeneity of the teams notably influenced the hackathon results. Observing all the teams that participated in the four hackathons and the corresponding solution proposals, there is a correlation between the diversity of profiles and the innovativeness of the outcome or at least the relevance of the solution for the local administration. The teams with more competencies among their members proposed more creative, valuable, and user-friendly results. Moreover, having not only developers or other technical profiles but a combination of designers, project managers, migration workers, and even lawyers resulted in the development of ideas with human-centred perspectives, which constituted a significant advantage due to the (humanities-related) nature of the hackathon scope.

Despite the easyRights technical solutions development being a separate project activity, a collaborative strategy ensured the registered participants could access additional knowledge and information about the solutions as early as possible in the hackathon journey to inspire their ideas. As already underlined, the easyRights hackathons were designed to embrace not only technical or coding profiles but also other profiles who were, in many cases, unfamiliar with technical specifications or lacked technical or coding languages. Considering the mix of participant profiles regarding their technical level, the offered approach to the easyRights solutions had to embrace such diversity and cover both the functional and mechanical understanding needs.

To facilitate the understanding of the functionalities and scope of the three solutions, user cases were developed and illustrated for the hackathon participants. Each of the user cases displayed a possible scenario of the integration of the easyRights solutions into the target service. Aware of the restricting challenges of our hackathons, the user cases were deliberately designed to serve as an inspirational reference for the teams and served as the introduction card for the technical solutions during the hackathon preparation calls. This same introduction of the solutions through the user cases was repeated at the initial session of each local hackathon.

After introducing the user case narratives, the project technical team also presented each of the easyRights solutions in both the preparation calls and the initial session of each local hackathon. They concretised all the technical details and components of each solution and showed some state-of-the-art mock-ups. Lastly, to encourage the experiential familiarisation of participants with the solutions that needed to be integrated into the proposal, the attendees were invited to access and interact with them as a strategic advantage for the event.

However, despite the efforts to instigate the interaction of participants with the project solutions prior to or during the event, none of the invitations sent by the digital team to the attendees' email addresses was used. The lack of the teams' interaction with the easyRights solutions may be one of the causes of the low level of integration of the easyRights solutionsoriented to language skills development in the generated proposals during the first cycle of hackathons. Surprisingly, the teams integrated Google Translate for some features in their solutions that could have been approached using language courses or pronunciation training, indicating their lack of understanding of these two easyRights technical solutions. Differently, the third easyRights technical component - the pathway generator-was always adopted by the teams, demonstrating that the presentation of the challenge in relation to the procedural complexity was adequately transferred to the participants.

\section{5. easyRights Preliminary Findings}

The easyRights project is proving that services access, and consequently rights exercise, is a multifaceted and complex issue that challenges the process. Therefore, inclusive wideranging methodologies are essential to evaluate and reformulate access to such services. 
The described easyRights framework - combining co-design and learning - is necessary to approach the complex structures in which services are embedded (Concilio et al. 2021).

The application of this framework showed that co-design could play a double role in making the easyRights project. On one hand, the use of human-centred tools by a large number of actors-both familiar and not with the service procedure-to analyse the ecosystem of a service, depict their steps, and the user experience resulted in a solid understanding of the accessibility issues faced by migrants. In other words, applying co-design tools aligned the involved actors towards the operational dimension of the integration goal and contributed to operating a situational approach for sense-making in complex contexts such as migrants' integration, resonating with the words of Oduntan and Ruthven (2020). On the other hand, co-design also provided the conditions for immigrants to take an active part in the design of the service ecosystem, thus making the service development process an integration moment itself.

Additionally, thanks to the introduction of the above-mentioned tools among actors of the service ecosystem that are unfamiliar with participatory design methodologies, such as service design, a learning process occurred. The perceived impact of co-creating purposeful solutions inspired the participating stakeholders involved in service provision to apply human-centred strategies in the design or redesign of their offered service. Such findings corroborate Lodato and DiSalvo's ideas on the benefit of hackathons for proving public institutions the potential of co-design events for innovation in the public realm (Lodato and DiSalvo 2018). The extended hackathon format used by easyRights was validated as a process to inspire and demonstrate how the involvement of stakeholders for re-designing public services can generate relevant, context-rooted and human-centred solutions that improve the adoption and experience of the public services provided.

Moreover, through the hackathon events, the easyRights project applied such a codesign learning framework with the aim of improving the access of immigrants to existing public services in the four pilot cities. In addition, hackathons may be considered special co-design contexts with a special focus on ICT solutions. We have noticed that co-designing ICT solutions in diverse and open environments, such as easyRights hackathons, was not an easy task, considering the amount of technical and infrastructural requirements of the existing services and technologies on one hand and the skills and devotion of participants on the other hand-without forgetting the added obstacles caused by the impact of the COVID-19 pandemic.

Despite the intense attention posed to the ICT dimension in the preparation of the hackathons, the multidimensional nature of the accessibility made the plurality of the hackathon environments not prone to deal with it, mainly focusing on one or on a limited number of aspects of the accessibility issues. This also becomes more evident from the outcomes of the first cycle hackathon's solutions for the four pilot locations. For instance, the final solution in the Birmingham hackathon focused on a translation widget using easyRights technology in audio and written format for the city's air quality permit website. In Larissa, the winning team proposed automation of the immediate storage and management of data related to application for and issue of certificates of permanent residence. In Malaga, the hackathon's result was a voice assistant that applied easyRights technology to complement services with a narrated experience in the migrants' language. Finally, in Palermo, the hackathon solution was an application that facilitated the understanding of the steps necessary to access the registry services of the Municipality.

Nevertheless, all hackathons have proven to be an effective and promising environment to apply co-design to make existing services more accessible to immigrants, guaranteeing them easier access to their rights. They also proved that linguistic gaps and bureaucratic complexities play relevant roles in the inaccessibility of services. The results of easyRights hackathons also confirm the potential of the technological solutions stemming from this project, aimed at providing migrants with the language knowledge and skills they need for elementary everyday transactions, but also at guiding them in relation to the 
complex and often ambiguous administrative procedures they are required to perform in the process of their actual integration into the host communities.

Based on what we have learned and experienced from the easyRights hackathons, the outcomes of the project pursue the configuration of societies based on active citizenship and equal opportunities by means of digital tools that contribute to improving access to public procedures and guarantee at least basic human rights. As suggested by Stephanidis et al. (2019), migrants' participation in learning that includes technological innovations can encourage new viewpoints in relation to other mobile populations, such as students and workers communities. Within the same frame of thought, the globalisation of migration and its related social challenges should be approached as an opportunity for technology to demonstrate its full potential by exploiting the human and digitalisation interface for the benefit of everybody. According to Kukulska-Hulme (2019), in the world of "humantechnology symbiosis", technology is expected to adapt itself to the needs of multicultural societies by mitigating social differences and providing opportunities for active democratic citizenship.

Still on-going, easyRights is currently devoted to the application of the full potential of human-technology symbiosis for mitigating social differences through the redesign of the services selected for the second cycle of the project. As the initial pre-hackathon stage comes to its conclusion by the time this article is being written, some of the mentioned insights are reinforced.

Like the first cycle of hackathons, this new loop of hackathons is proving to be an excellent scenario to bring together a variety of actors to critically look and act upon the serious gap between how services for immigrants should work and how they are actually experienced. As the complexity and intricacy of the targeted procedures become evident using service design tools, so does the realisation of the absolute need for a united, multifaceted, and inclusive approach when designing services for migrants. The multiple possibilities offered by ICTs have been demonstrated as key strategies for immigrants to overcome the language barriers and bureaucratic and idiomatic complexities to access services in this ambitious goal that easyRights is determined to keep working toward.

Author Contributions: Conceptualisation, G.C. (Grazia Concilio) and M.K.; investigation, M.K.; methodology, G.C. (Grazia Concilio); supervision, G.C. (Grazia Concilio) and M.K.; validation, M.V.d.O.; writing—original draft, G.C. (Grazia Concilio); writing—review and editing, G.C. (Grazia Concilio), G.C. (Giuliana Costa), M.K., M.V.d.O., and O.K. All authors have read and agreed to the published version of the manuscript.

Funding: The easyRights project is funded by EU Horizon 2020, grant number 870980 . However, the opinions expressed herewith are solely the authors and do not necessarily reflect the point of view of any EU institution.

Informed Consent Statement: This article is written in compliance with the General Data Protection Regulation of the European Union and the provisions of national legislation Data Protection Act 2018. Additionally, informed consent was obtained from all subjects involved in the study.

Conflicts of Interest: The authors declare no conflict of interest.

\section{Notes}

1 These words have been said by Alberto Sinigallia, director of Fondazione Progetto Arca (https://www.progettoarca.org, accessed on 10 December 2021) in Milan, October 2017 during an interview carried out by one the authors of this article. A European network of 52 churches and Christian NGOs providing social and health care services and advocating social justice. Growing racism and xenophobia and lack of implementation of the EU directive by member states often violate human rights and freedom were identified as the first and second, respectively.

4 The Quadruple Helix stakeholder communities compose the easyRights pilot sites, including actors from academia, business, civil society, and government. (See Section 4.2 in this article for more detailed information).

5 https://www.senato.it/istituzione/la-costituzione/parte-i/titolo-ii/articolo-32 (accessed on 15 January 2022). 
6 Developed at Norwegian University of Science and Technology (NTNU) (https://www.ntnu.edu/isl/calst). (accessed on 20 January 2022).

7 One example of the use of NLP is Portale immigrazione in Italy, a portal dedicated to the procedures for issuing and renewing permits and residence cards, promoted by the Ministry of the Interior in collaboration with the Italian Post Office and the National Association of Italian Municipalities (ANCI) (for more information see https: / www.portaleimmigrazione.it) (accessed on 20 January 2022).

\section{References}

Abramovitz, Mimi, and Jennifer Zelnick. 2015. Privatization in the Human Services: Implications for Direct Practice. Clinical Social Work Journal 43: 283-93. [CrossRef]

Barberis, Eduardo, and Izabela Buchowicz. 2015. Creating Accessibility to Education: The Role of School Staff's Discretionary Practices. European Education 47: 61-76. [CrossRef]

Bauder, Harald, and Dayana A. Gonzalez. 2018. Municipal Responses to 'Illegality': Urban Sanctuary across National Contexts. Social Inclusion 6: 124-34. [CrossRef]

Bauder, Harald. 2016. Sanctuary Cities: Policies and Practices in International Perspective. International Migration 55: 174-87. [CrossRef] Bobeth, Jan, Stephanie Schreitter, Susanne Schmehl, Stephanie Deutsch, and Manfred Tscheligi. 2013. User-Centered Design between Cultures: Designing for and with Immigrants. In INTERACT 2013. Part IV, LNCS 8120. Edited by Paula Kotzé, Gary Marsden, Gitte Lindgaard, Janet Wesson and Marco Winckler. Berlin and Heidelberg: Springer, pp. 713-20.

Brown, Tim, and Barry Katz. 2019. Change by Design: How Design Thinking Transforms Organizations and Inspires Innovation. New York: HarperBusiness, vol. 20091.

Bustamante, Duarte, Ana Maria, Auriol Degbelo, and Christian Kray. 2018. Exploring Forced Migrants (Re)settlement \& the Role of Digital Services. In Proceedings of 16th European Conference on Computer- Supported Cooperative Work. Exploratory Papers, Reports of the European Society for Socially Embedded Technologies. Nancy: European Society for Socially Embedded Technologies, ISSN 2510-2591. [CrossRef]

Callahan, Ewa. 2006. Interface design and culture. Annual Review of Information Science and Technology 39: 255-310. [CrossRef]

Caponio, Tiziana, and Michael Jones-Correa. 2018. Theorising migration policy in multilevel states: The multilevel governance perspective. Journal of Ethnic and Migration Studies 44: 1995-2010. [CrossRef]

Carayannis, Elias G., and David F. J. Campbell. 2009. "Mode 3" and "Quadruple Helix": Toward a 21st century fractal innovation ecosystem. International Journal of Technology Management 46: 201. [CrossRef]

Carr, Sara Jensen, and Allison Lassiter. 2017. Big Data, Small Apps: Premises and Products of the Civic Hackathon. In Seeing Cities Through Big Data. Cham: Springer Geography, pp. 543-59. [CrossRef]

Codagnone, Cristiano, and Stefano Kluzer. 2011. ICT for the Social and Economic Integration of Migrants into Europe. Joint Research Centre, Institute for Prospective Technological Studies, European Commission. Luxembourg: Publiction Office of the European Union.

Collin, Simon, and Thierry Karsenti. 2012. Facilitating linguistic integration of immigrants: An overview of ICT tools. Issues in Informing Science and Information Technology 9: 243-51. [CrossRef]

Concilio, Grazia, Maryam Karimi, and Lydia Rössl. 2021. Complex Projects and Transition-Driven Evaluation: The Case of the easyRights European Project. Sustainability 13: 2343. [CrossRef]

Costa, Giuliana, and Benjamin Ewert. 2014. Cities of migration: The challenges of social inclusion. In Social Vulnerability in European Cities. The Role of Local Welfare in Times of Crisis. Edited by Taco Brandsen, Stefania Sabatinelli and Costanzo Ranci. London: Palgrave.

Dahinden, Janine. 2016. A plea for the 'de-migranticization' of research on migration and integration. Ethnic and Racial Studies 39: 2207-25. [CrossRef]

Deloitte. 2019. eID/mID for Migrants Assessing Future RED in the Field of Identification. A Study Prepared for the European Commission DG Communications Networks, Content \& Technology. Luxembourg: Publiction Office of the European Union.

Design Council. 2007. 11 Lessons Managing Design in 11 Global Brands. London: UK Design Council.

Diminescu, Dana. 2008. The connected migrant: An epistemological manifesto. Social Science Information 47: 565-79. [CrossRef]

easyRights D1.5. 2021. The easyRights Deliverable 1.5: The easyRights Mediation Grammar 1. Forthcoming. Available online: https:/ / www.easyrights.eu/deliverables (accessed on 15 December 2021).

easyRights D3.1. 2021. The easyRights Deliverable 5.1: Hackathon Guidelines. Forthcoming. Available online: https://www.easyrights. eu/deliverables (accessed on 15 December 2021).

easyRights D5.1. 2020. The easyRights Deliverable 5.1: Triple Loop Learning Mechanisms. Forthcoming. Available online: https: / / www.easyrights.eu/deliverables (accessed on 15 December 2021).

Eurodiaconia. 2014. Access to Social and Health Services for Migrants in Europe: Overcoming the Barriers Policy Recommendations and Good Practice from Diaconal Service Providers, Bruxelles, Belgium. Available online: https://www.eurodiaconia.org/ (accessed on 15 December 2021).

Farbenblum, Bassina, Laurie Berg, and Angela Kintominas. 2018. Transformative Technology for Migrant Workers: Opportunities, Challenges and Risks. New Work: Open Society Foundations.

Feigenbaum, Harvey B., and Jeffrey R. Henig. 1994. The Political Underpinnings of Privatization: A Typology. World Politics 46: 185-208. [CrossRef] 
Feldman, Gregory. 2020. We Are All Migrants. Redwood City: Stanford University Press.

Fertig, Michael, and Christoph M. Schmidt. 2001. First-and Second-Generation Migrants in Germany-What Do We Know and What Do People Think? Available online: https:/ / portal.cepr.org/discussion-paper/6127 (accessed on 10 December 2021).

Finch, Ruth. 2016. Urban Policies and the Intercultural City: A Reflection on Norms and Contexts. In The Intercultural City. Migrations, Minorities and the Management of Diversity. Edited by Giovanna Marconi and Elena Ostanel. London: I.B.Tauris.

Foner, Nancy. 2007. How exceptional is New York Migration and Multiculturalism in the Empire City. Ethnic and Racial Studies 30: 999-1023. [CrossRef]

Garrido, Maria, Joe Sullivan, and Andrew Gordon. 2009. Getting ahead in the knowledge society: The role of digital competences in advancing employability outcomes for immigrant women in the EU. Paper presented at the ACM International Conference Proceeding Series, London, UK, December 13-16.

Hachè, Alexandra, and Joe Cullen. 2009. ICT and Youth at Risk. How ICT-driven initiatives can contribute to their socio-economic inclusion and how to measure it. In Workshop Conclusions. Seville: Joint Research Centre, Institute for Prospective Technological Studies, European Commission.

Isin, Engin F., and Greg M. Nielsen, eds. 2008. Acts of Citizenship. London: Zed Books.

Joint Migration Policy Whitepaper. 2020. Towards ICT-Enabled Integration of Migrants. Available online: https:/ / digital-strategy.ec. europa.eu/en/news/migration-whitepaper-new-approach-digital-services-migrants / (accessed on 10 January 2022).

Kukulska-Hulme, Agnes. 2019. Mobile Language Learning Innovation Inspired by Migrants. Journal of Learning for Development 6: 116-29.

Lipsky, Michael. 1980. Street-Level Bureaucracy: The Dilemmas of the Individual in Public Services. New York: Russell Sage Foundation.

Lodato, Thomas, and Carl DiSalvo. 2018. Institutional Constraints: The Forms and Limits of Participatory Design in the Public Realm. In PDC '18: Proceedings of the 15th Participatory Design Conference-Volume 1, Hasselt and Genk, Belgium, 20-24 August 2018. New York: ACM, 12p. [CrossRef]

Long, Frank. 2009. Real or imaginary? The effectiveness of using personas in product design. Paper presented at the Irish Ergonomics Society Annual Conference, Dublin, Irland, May 28; Dublin: Irish Ergonomics Society, pp. 1-10.

Messina, Giovanni, and Gaetano Sabato. 2019. Frontiera e retoriche della migrazione: Il caso della carta di Palermo 2015. In Mondo Nuovo. Acta Geopolitica. È tornata l'Italia? Edited by Michel Korinman and Giuseppe Terranova. Ogliastro Cilento: Licosia, pp. 203-13.

Moe, Ronald C. 1987. Exploring the Limits of Privatization. Public Administration Review 47: 453-60. [CrossRef]

Morelli, Nicola, Amalia De Götzen, and Luca Simeone. 2021. Service Design Capabilities. Basingstoke: Springer Nature.

O'Neill, Onora. 2005. The Dark Side of Human Rights. International Affairs 81: 427-39. [CrossRef]

Oduntan, Olubukola, and Ian Ruthven. 2020. Situational Information Behaviour: Exploring the Complexity of Refugee Integration International Journal of Information, Diversity \& Inclusion 4: 5-21.

OECD. 2016. Making Integration Work: Refugees and Others in Need of Protection. Paris: OECD Publishing.

OECD. 2018. Working Together for Local Integration of Migrants and Refugees. Paris: OECD Publishing.

Pruitt, John, and Tamara Adlin. 2006. The Persona lifecycle: Keeping People in Mind throughout Product Design. San Francisco: Morgan Kaufmann.

Reichel, David, Melissa Siegel, and Juan Carlos Andreo Tudela. 2015. ICT for the Employability and Integration of Immigrants in the European Union: A qualitative analysis of a survey in Bulgaria, the Netherlands and Spain. In JRC Science and Policy Report: EUR 27354EN. Edited by Stephanie Carretero and Clara Centeno. Luxembourg: Publications Office of the European Union.

Rizzo, Francesca, Alessandro Deserti, and Onur Müstak Cobanli. 2016. Service design in public sector: Boosting innovation through design. In ServDes 2016. Linköping: Linköping University Electronic Press, pp. 448-57.

Ruhs, Martin, Kristof Tamas, and Joakim Palme. 2019. Bridging the Gaps: Linking Research to Public Debates and Policy Making on Migration and Integration. Oxford: Oxford University Press, p. 288.

Schiller, Nina Glick, and Ayse Çaglar, eds. 2011. Locating Migration: Rescaling Cities and Migrants. Ithaca: Cornell University Press.

Schneider, Jakob, Marc Stickdorn, Markus Edagar Hormess, and Adam Lawrence, eds. 2018. This Is Service Design Doing: Applying Service Design Thinking in the Real World: A Practitioners' Handbook. Sebastopol: O'Reilly Media.

Scholten, Peter, Fleur Baggerman, Linda Dellouche, Venja Kampen, Julia Wolf, and Rick Ypma. 2017. Policy Innovation in Refugee Integration? A Comparative Analysis of Innovative Policy Strategies toward Refugee Integration in Europe. Rotterdam: Erasmus University Rotterdam.

Spotti, Massimiliano, and Jeanne Kurvers. 2015. ICT-Based Applications for Civic Integration in The Netherlands: Policy Drivers and Limits in Practice. Abingdon: Routledge, pp. 187-99.

Stephanidis, Constantine, Gavriel Salvendy, Margherita Antona, Jessie Y. C. Chen, Jianming Dong, Vincent G. Duffy, Xiaowen Fang, Cali Fidopiastis, Gino Fragomeni, Limin Paul Fu, and et al. 2019. Seven HCI Grand Challenges. International Journal of Human-Computer Interaction 35: 1229-69. [CrossRef]

Stickdorn, Marc, Markus Edgar Hormess, Adam Lawrence, and Jakob Schneider. 2018. This Is Service Design Doing: Applying Service Design Thinking in the Real World. Sebastopol: O'Reilly Media.

Sullivan, Harold J. 1987. Privatization of Public Services: A Growing Threat to Constitutional Rights. Public Administration Review 47: 461-67. [CrossRef] 
Taylor, Nick, and Loraine Clarke. 2018. Everybody's Hacking: Participation and the Mainstreaming of Hackathons. In Proceedings of the 2018 CHI Conference on Human Factors in Computing Systems. Paper 172. New York: Association for Computing Machinery, pp. 1-12. [CrossRef]

Vargas-Silva, Carlos, and Cinzia Rienzo. 2019. Migrants in the UK: An Overview. Briefing Paper. Oxford: Migration Observatory, University of Oxford.

Vertovec, Steven. 2007. 'Super-diversity' and its implications. Ethnic and Racial Studies 29: 1024-54. [CrossRef]

Von Hippel, Eric. 2005. Open source software projects as user innovation networks- no manufacturer required. In Perspectives on Free and Open Source Software. Edited by Joseph Feller, Brian Fitzgerald, Scott A. Hissam and Karim R. Lakhani. Cambridge: MIT Press, pp. 267-78.

Warner, Mildred E. 2008. Reversing privatization, rebalancing government reform: Markets, deliberation and planning. Policy and Society 27: 163-74. [CrossRef] 